\title{
IUFOST2006/63 \\ Effect of temperature in the behaviour of pectin methylesterase. Differences between roof and leafy vegetables
}

\author{
D. Rico ${ }^{\text {a }}$, A.B. Martin-Diana ${ }^{\mathrm{a}}$, J. Mulcahy ${ }^{\mathrm{a}}$, C. Barry-Ryan ${ }^{\mathrm{a}}$, G. Henehan ${ }^{\mathrm{a}}$ and J. Frias ${ }^{\mathrm{b}}$ \\ ${ }^{a}$ Dublin Institute of Technology, Sackville Place, 1 Dublin, Ireland \\ ${ }^{\mathrm{b}}$ School of Food Science and Environmental Health, Dublin Institute of Technology, Cathal Brugha St, 1 \\ Dublin, Ireland \\ jesus.frias@dit.ie
}

Fresh-cut vegetables have gained acceptance during the recent years by the consumers due to the new trends in life style. The consumers demand fresh, healthy and convenient foods. The textural changes of fruits and vegetables are related with enzymatic and non-enzymatic processes. Enzymatic degradation is catalysed by pectin methyl esterase and polygalacturonase. The pectin first is partially demethylated by PME, resulting in a lower degree of methylation and polygalacturonic acid and the latter will be depolymerised by PG. This causes a drastic loss of texture. The stimulation of PME at temperatures between $50{ }^{\circ} \mathrm{C}$ to bleaching conditions has been correlated with texture maintenance. The maintenance is due to the favourable effect in the limited beta-elimination and to complex formation of demethylated pectin with calcium ions.

The aim of this work was evaluate the effect of temperature on the PME extracted from two different types of vegetables, lettuce and carrot. The study of the effect of PME in the different tissue was also evaluated (peel and core for carrot, vascular and photosynthetic for lettuce). Since the activation of PME is related with the enhancement of the texture optimised the time and temperature was the main objective for leafy and root vegetables.

The denaturation kinetics of pectin methylesterase (PME) present in carrot and lettuce were studied. Fresh extracts from the vegetables were exposed to four levels of temperature $(55,60,65,70)$ till activity extinction. A model based on the presence of two forms of the enzyme, one active and one non-active (proto enzyme), was proposed. Mixed effects modelling was used to cope with the natural variability of the enzyme activity values found .

No differences in PME activity values were found for the different fresh tissues of the lettuce (vascular and photosynthetic), while in carrots the differences were observed. Peel showed significant higher (p\&_lt;0.05) values than core. Model parameters obtained describing the kinetics of the enzyme degradation were not significantly different for the two vegetables (p\&_lt;0.05), supporting the hypothesis of a common enzyme. 